\title{
Correlating the Plant Height of Wheat with Above- Ground Biomass and Crop Yield Using Drone Imagery and Crop Surface Model, A Case Study from Nepal
}

\author{
Uma Shankar Panday ${ }^{1}{ }^{(0}$, Nawaraj Shrestha ${ }^{1}$, Shashish Maharjan ${ }^{1,2}$, Arun Kumar Pratihast ${ }^{3}{ }^{(}$, \\ Shahnawaz ${ }^{4}$, Kundan Lal Shrestha ${ }^{5}$ and Jagannath Aryal 1,6,*(D) \\ 1 Department of Geomatics Engineering, School of Engineering, Kathmandu University, Dhulikhel 45200, \\ Nepal; uspanday@ku.edu.np (U.S.P.); nawa.shrestha@ku.edu.np (N.S.); shashish.maharjan@cgiar.org (S.M.) \\ 2 International Maize and Wheat Improvement Center, Khumaltar, Lalitpur 44700, Nepal \\ 3 Wageningen Environmental Research, Wageningen University and Research, 6708 PB Wageningen, \\ The Netherlands; arun.pratihast@wur.nl \\ 4 Interfaculty Department for Geoinformatics-Z_GIS, University of Salzburg, 5020 Salzburg, Austria; \\ s.shahnawaz@sbg.ac.at \\ 5 Department of Environmental Science and Engineering, School of Science, Kathmandu University, \\ Dhulikhel 45200, Nepal; kundan@ku.edu.np \\ 6 Department of Infrastructure Engineering, Melbourne School of Engineering, The University of Melbourne, \\ Melbourne, VIC 3010, Australia \\ * Correspondence: Jagannath.Aryal@unimelb.edu.au
}

Received: 30 May 2020; Accepted: 28 June 2020; Published: 1 July 2020

\begin{abstract}
Food security is one of the burning issues in the 21st century, as a tremendous population growth over recent decades has increased demand for food production systems. However, agricultural production is constrained by the limited availability of arable land resources, whereas a significant part of these is already degraded due to overexploitation. In order to get optimum output from the available land resources, it is of prime importance that crops are monitored, analyzed, and mapped at various stages of growth so that the areas having underdeveloped/unhealthy plants can be treated appropriately as and when required. This type of monitoring can be performed using ultra-high-resolution earth observation data like the images captured through unmanned aerial vehicles (UAVs)/drones. The objective of this research is to estimate and analyze the above-ground biomass (AGB) of the wheat crop using a consumer-grade red-green-blue (RGB) camera mounted on a drone. AGB and yield of wheat were estimated from linear regression models involving plant height obtained from crop surface models (CSMs) derived from the images captured by the drone-mounted camera. This study estimated plant height in an integrated setting of UAV-derived images with a Mid-Western Terai topographic setting ( 67 to $300 \mathrm{~m}$ amsl) of Nepal. Plant height estimated from the drone images had an error of $5 \%$ to $11.9 \%$ with respect to direct field measurement. While $\mathrm{R}^{2}$ of 0.66 was found for AGB, that of 0.73 and 0.70 were found for spike and grain weights respectively. This statistical quality assurance contributes to crop yield estimation, and hence to develop efficient food security strategies using earth observation and geo-information.
\end{abstract}

Keywords: wheat; remote sensing; AGB; crop yield; estimation; crop monitoring; consumer drone; digital camera 


\section{Introduction}

Food security is one of the burning issues in the 21st century [1,2]. The world, with an ever-growing population, has increased demands on food production systems [1]. However, agricultural production is inadequate due to the limited availability of arable land resources that are degraded due to overexploitation, and it poses a threat to food security to a significant part of the society since it limits the yield of the crops, compels farmers to apply more inputs, and may ultimately force the farmers to abandon the agricultural land [3]. In a bigger picture scenario, the problem is further worsened by global changes such as climate change [4,5], land use/land cover change [6-8], and desertification [7,9]. Although the production has been increased by the use of efficient technologies and high yielding varieties of various cereals, low-income countries like Nepal lag behind in these areas. So, to get the optimum output from the limited resources, it is of prime importance that crops are monitored, analyzed, and mapped at various stages of growth so that the areas affected by underdeveloped/unhealthy plants can be treated properly and as early as possible [10]. The focus of this research was wheat (Triticum spp.) which is the third most important cereal crop, after rice and maize, in Nepal. However, the average productivity of wheat is very low as compared to developed countries [11]. A number of aspects make planning and managing wheat crop using satellite images quite challenging in Nepal. First, the average farm size in Nepal is 0.46 ha [12], which limits the applicability of openly/freely available satellite imagery at the farm level to derive meaningful above-ground biomass (AGB) estimates. Second, like many cereal crops, wheat has a short lifespan of approximately five months. This short lifespan makes meaningful monitoring very expensive. Third, most of the wheat-growers are small-holder farmers who generally lack the resources to recover from a wrong decision. Hence, there is an urgent need to use efficient technologies in monitoring wheat crops and estimate yields for developing adaptation strategies and mitigating adverse effects.

Currently, two main types of satellite remote-sensing data, namely optical imagery and synthetic aperture radar (SAR), have been widely used to estimate the plant characteristics and thus relate it to AGB, yield, crop management, and optimization. However, the operational use of these satellite data at a farm level is difficult due to their limited spatial and spectral resolutions. Further, the longer revisit frequency of satellite sensors, resulting in products with a lack of temporal availability is another concern in operational use. Recently some researchers have attempted to acquire higher spatial resolution farm level light detection and ranging (LiDAR) data [13-15]. One of the advantages of LiDAR data is 3-D representations of plants that provide a precise crop surface model (CSM) estimate [13-15]. However, LiDAR scanners are costly [13] and the availability of these datasets are limited for the areas of interest in low-income countries. Therefore, a high-resolution digital camera mounted on an unmanned aerial vehicle (UAV), or commonly known as a drone, can also be used for generating CSM $[16,17]$. UAVs, sometimes referred to as remotely-piloted aerial systems (RPAS) or unmanned aerial systems (UAS), are one of the emerging tools to be used for small-scale remote sensing [18-20].

AGB is one of the important parameters that helps to assess and estimate yield, crop health, nutrient supply, nitrogen nutrient index (NNI), and management practices [21]. Therefore, regular monitoring of crop AGB helps to inform the farmers and practitioners to make informed decisions at the appropriate time. Crop AGB and yield can be estimated through crop parameters such as plant height $[10,15,16,22-25]$, leaf area index (LAI) [10,26], and vegetation indices $[10,16,24,26]$. Plant height, which is either measured at ground level or obtained using photogrammetric techniques such as crop surface models (CSMs) [15,16,23,25], can be used to estimate the AGB. Plant height is highly suitable for AGB estimation as it can be easily measured for barley [10], paddy rice [15], black oat [25], and sugar beet [23]. Similarly, a strong correlation exists between plant height and grain yield in barley, oat and wheat [14], and in oilseed rape, winter rye, winter wheat, and grassland [22]. Studies have found that black oat AGB can be estimated using the plant height that is derived from RGB images acquired with a drone which can be derived from CSMs [25]. Fresh and dry AGB of black oat can be predicted from plant height obtained from the drone images [25]. Likewise, pasture AGB can be estimated using 
a similar approach [27]. AGB estimation of maize using linear and exponential regression models is comparatively analyzed, along with the use of vegetation indices [24]. The multivariable linear regression model was reported to provide the best results by this study [24]. Plant height can be estimated from 3D point cloud datasets alone [24], and using drone-based 3D point cloud datasets and statistical analysis that used a moving cuboid filter to remove outliers [28]. Comparisons of drones with airborne platforms (for larger areas) and terrestrial laser scanning (TLS) show similar results [14].

This study aims to develop a drone-based wheat monitoring, AGB, and yield estimation system that can help overcome the challenges posed by monitoring wheat crops with satellite images. We use drone-based data from a small-scale winter field experiment to evaluate how successfully the CSMs can predict AGB and crop yield. Collecting drone-based RGB-images is simple and cost-effective. This study estimated the AGB and crop yield of wheat by using the plant height that is derived from consumer-grade RGB drone images in Nepal (Figure 1). We also analyzed the performance of the models based on plant height. The specific aims of this study are:

1. to understand how the easily measurable plant parameters such as plant height can be used to infer crop AGB, yield, and fertilizer optimization;

2. to develop empirical regression models between the plant height and the AGB, and the plant height and the yield for wheat crops; and

3. to validate empirical models for AGB and yield estimation with field measurements.

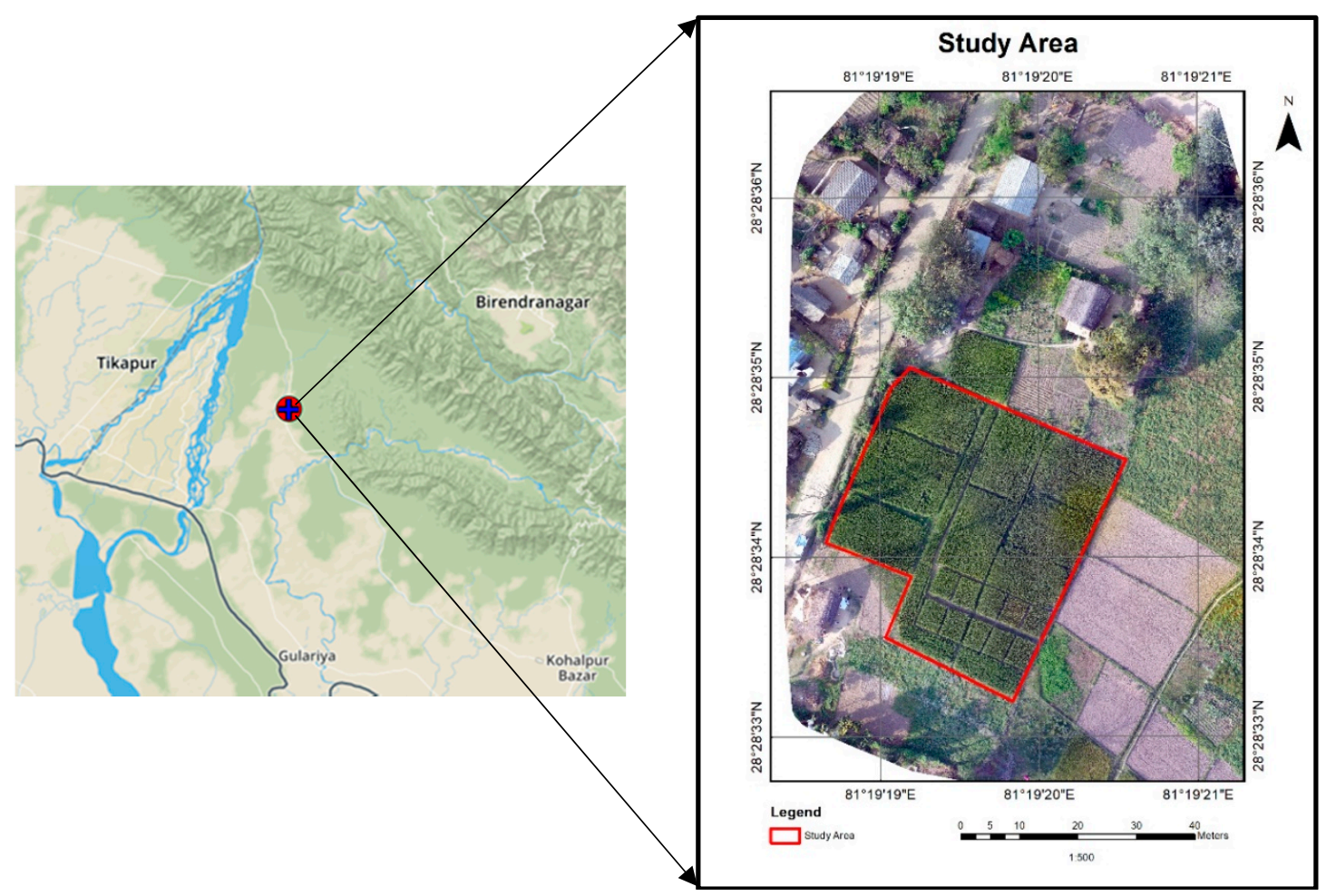

Figure 1. The study area in Bardiya District, Nepal. The inset map shows the study area as a red polygon overlaid on a red, green, and blue composite image acquired by a drone with a spatial resolution of $0.01 \mathrm{~m}$.

\section{Materials and Methods}

\subsection{Study Area}

A wheat field at Bhurigaun village of Bardiya District, Nepal was selected as the study area (Figure 1). The study site was managed by the International Maize and Wheat Improvement Center 
(CIMMYT). Ten trial plots and four demonstration plots were used in the experimental design. The trial plots (named T1 to T10) had a uniform area of $20 \mathrm{~m}^{2}$. Four demonstration plots named A, B, C, and $\mathrm{D}$ (Plot D is managed by the farmer and known as the farmer's plot) had an area of 600, 300, 300, and $100 \mathrm{~m}^{2}$ respectively. Sowing in the demonstration plots was done on 25 November 2017, while in the trial plots it was done on 26 November 2017. The crops from all the plots were harvested on 11 April 2018.

Trial plots were used to make experiments, whilst demonstration plots were prepared for demonstrating the outcomes to the farmers and comparing the results with the plot managed by the farmers themselves. Experiments on the application of fertilizers and management practices were made on trial plots by CIMMYT. The plot giving optimum results were replicated the next year in demonstration plots. Different amounts and types of fertilizers and diverse management practices were applied, which are presented in Tables 1 and 2.

Table 1. Fertilizer application and treatment method in demonstration plots. Various types and amounts of fertilizers and different management practices are employed in these plots.

\begin{tabular}{ll}
\hline Plot & Fertilizer Application/Treatment \\
\hline \multirow{3}{*}{ Plot A } & 120: $50: 10 \mathrm{Kg} /$ ha $\mathrm{NP}_{2} \mathrm{O}_{5} \mathrm{~K}_{2} \mathrm{O}+$ best management practices (BMP) \\
& $\begin{array}{l}\text { Wheat variety: Bijaya [29] } \\
\text { Sowing method: Line sowing of seeds } \\
\text { Fertilizer application: Machine }\end{array}$ \\
& 120: 50: $10 \mathrm{Kg} / \mathrm{ha} \mathrm{NP}_{2} \mathrm{O}_{5} \mathrm{~K}_{2} \mathrm{O}+\mathrm{BMP}$ \\
Plot B & Wheat variety: Bijaya \\
& Sowing method: Manual line sowing \\
& Fertilizer application: Manual line application \\
& 120: $50: 10 \mathrm{Kg} /$ ha $\mathrm{NP}_{2} \mathrm{O}_{5} \mathrm{~K}_{2} \mathrm{O}+$ BMP \\
Plot C & Wheat variety: Bijaya \\
& Sowing method: Precision broadcasting \\
& Fertilizer application: Precision broadcasting using Earthway spreader \\
\hline & Fertilizer rate: Farmer practices \\
Plot D & Wheat variety: Farmer choice (local seed variety was used by the farmer) \\
& Sowing method: Farmer choice \\
& Fertilizer application: Farmer choice
\end{tabular}

Table 2. Fertilizer application in trial plots. Various types and amounts of fertilizers, but the same management practice is employed in trial plots. Bijaya [29] seed variety was used in all of the trial plots.

\begin{tabular}{|c|c|}
\hline Plot & Fertilizer Application/Treatment \\
\hline $\mathrm{T} 1$ & 120:50:10 Kg/ha NP${ }_{2} 0_{5} \mathrm{~K}_{2} \mathrm{O}$ \\
\hline $\mathrm{T} 2$ & 6-ton compost+120:50:10 Kg/ha NP${ }_{2} 0_{5} \mathrm{~K}_{2} \mathrm{O}$ \\
\hline T3 & 6-ton farm-yard manure (FYM) +120:50:10 Kg/ha NP ${ }_{2} 0_{5} \mathrm{~K}_{2} \mathrm{O}$ \\
\hline $\mathrm{T} 4$ & $120: 0: 10 \mathrm{Kg} / \mathrm{ha} \mathrm{NP}{ }_{2} \mathrm{O}_{5} \mathrm{~K}_{2} \mathrm{O}$ \\
\hline T5 & $120: 25: 10 \mathrm{Kg} / \mathrm{ha} \mathrm{NP}{ }_{2} \mathrm{O}_{5} \mathrm{~K}_{2} \mathrm{O}$ \\
\hline T6 & $120: 100: 10 \mathrm{Kg} / \mathrm{ha} \mathrm{NP}{ }_{2} \mathrm{O}_{5} \mathrm{~K}_{2} \mathrm{O}$ \\
\hline $\mathrm{T} 7$ & 0:0:0 $\mathrm{Kg} \mathrm{NP}_{2} \mathrm{O}_{5} \mathrm{~K}_{2} \mathrm{O} / \mathrm{ha}$ \\
\hline $\mathrm{T} 8$ & 80:50:10 Kg NP $20_{5} \mathrm{~K}_{2} \mathrm{O}$ Nitrogen from Polymer Coated Urea \\
\hline T9 & 120:50:10 Kg NP${ }_{2} \mathrm{O}_{5} \mathrm{O}$ Nitrogen from Polymer Coated Urea \\
\hline T10 & 120:50:10 Kg NP $20_{5} \mathrm{~K}_{2} \mathrm{O}+10$ ton/ha Rice fly ash \\
\hline
\end{tabular}

\subsection{Methods}

Twelve ground control points (GCPs) were established in the study area whose 3D-coordinates were measured using the differential global positioning system (DGPS). While six of them were used for orthorectification of the images, the rest were used as independent checkpoints to access the accuracy 
of the ortho-mosaic and digital surface model (DSM). The distribution of GCPs in the study area is depicted in Figure 2.

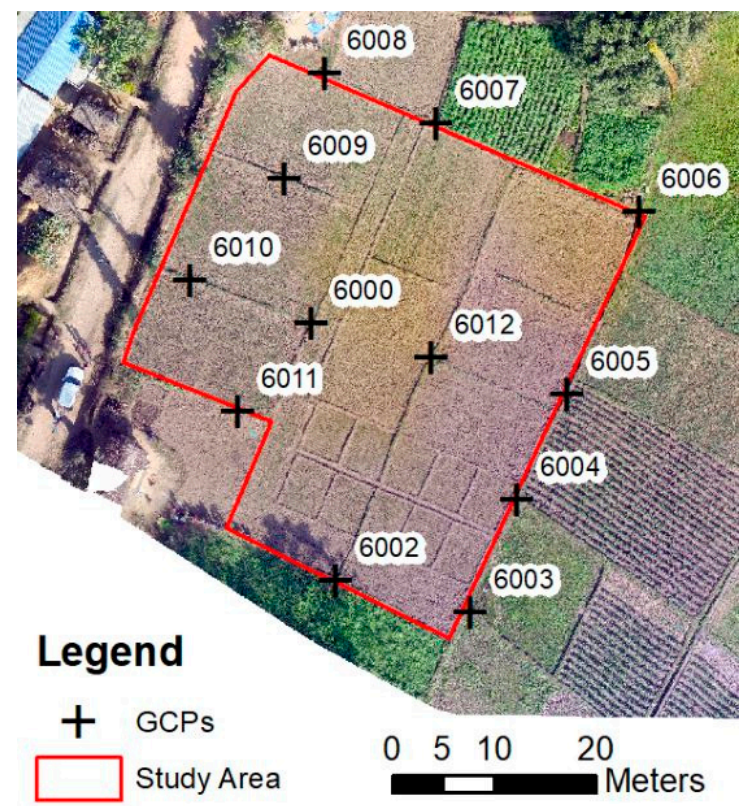

Figure 2. Ground control points (GCPs) distribution in the study area. The ortho-mosaic of the area from December 2017 is shown in the background.

A DJI Phantom 3 Advanced (https://www.dji.com/phantom-3-adv/info) drone was flown four times to capture the status of the wheat crop during each stage of its growth. Days after sowing (DoS), growth stage, date of drone flight, and the number of images captured are presented in Table 3. The first flight was conducted to prepare the bare earth elevation model of the study area. This reference surface was used to prepare CSM for the later stages by subtracting the reference surface elevation from the surface model of the particular stage.

Table 3. Drone flight date and the number of images collected during different growth stages. The number of images differed due to the unavailability of high-resolution satellite images for flight planning and hence, the educated guess was applied.

\begin{tabular}{|c|c|c|c|c|}
\hline Growth Stage [30] & Days after Sowing & Flight Date & No. of Images & Remarks \\
\hline & 13 & 8 December 2017 & 46 & \multirow{4}{*}{$\begin{array}{l}\text { As the zoom level of background } \\
\text { images for flight planning was low, } \\
\text { flight plans were prepared based on an } \\
\text { educated guess thereby varying the area } \\
\text { (and the number of images) covered. }\end{array}$} \\
\hline Terminal spikelet & 42 & 6 January 2018 & 62 & \\
\hline Heading & 105 & 10 March 2018 & 79 & \\
\hline Physiological maturity & 130 & 4 April 2018 & 60 & \\
\hline
\end{tabular}

Drone images were georeferenced and ortho-mosaics were prepared using Pix4DMapper Desktop (https://www.pix4d.com/). GCPs measured using DGPS were used to improve the accuracy of the ortho-mosaics, DSMs, and the products derived from the drone images. Using these DSMs, CSMs for the three growth stages were obtained by differentiating the bare earth elevation of the first flight from that of the particular growth stage. The plant height was then estimated from the CSM using the following steps.

First of all, a $1 \mathrm{~m} \times 1 \mathrm{~m}$ grid was generated (Figure 3). Then the average plant height for each of the grid was calculated from the CSM. The plant height of each of the plants falling inside the sample sub-plots within each plot was measured in the field, and the average plant height per sub-plot was calculated. The plant height obtained from the CSM was validated against the field-measured average plant height for the corresponding sample sub-plots. A quadrat of size $0.25 \mathrm{~m} \times 0.25 \mathrm{~m}$ was defined for 
field-based plant height measurement. Height of all the plants falling within the quadrat was measured and their mean was computed. Three samples per trial plot and five samples per demonstration plot were measured from the field to validate the plant height obtained from the CSM. The plant height was measured and validated against field-based measurements, at three growth stages: terminal spikelet (6 January 2018), heading (10 March 2018), and physiological maturity (4 April 2018).

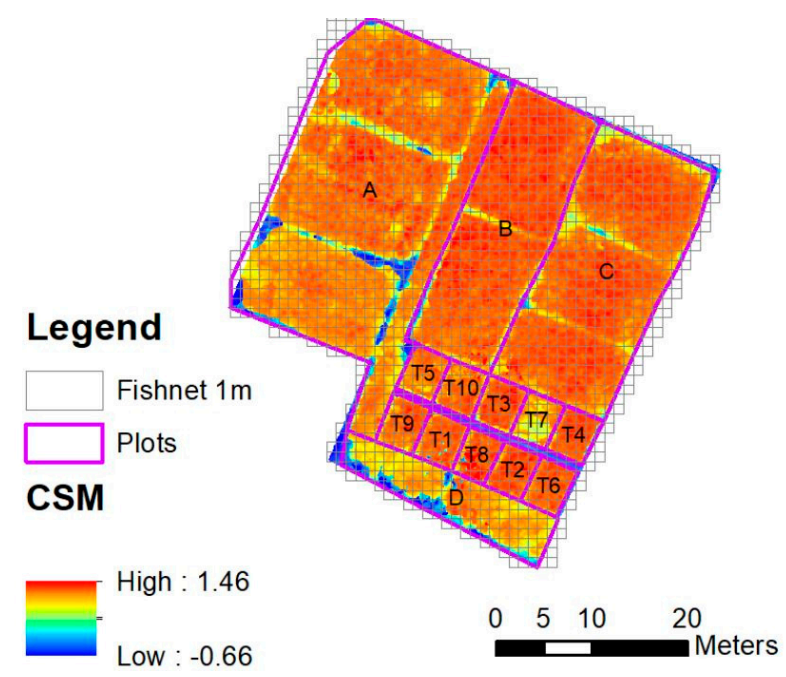

Figure 3. $1 \mathrm{~m} \times 1 \mathrm{~m}$ grid overlaid over the crop surface model (CSM) derived from March 2018 drone images. The average plant height for each of the grid was calculated from the CSM which were used in the regression models.

For AGB and crop yield sampling, quadrat sizes of $0.5 \mathrm{~m} \times 0.5 \mathrm{~m}$ and $2 \mathrm{~m} \times 2 \mathrm{~m}$ were used respectively for trial and demonstration plots. While two measurements were made in individual trial plots, three measurements were taken from each of the demonstration plots. Hence, data collected from these thirty-two sample locations were used for the development and validation of the AGB and crop yield models. While AGB and crop yield samples were taken from the harvesting stage, the plant height was used from the heading stage (March datasets). The developed relations/models were used to estimate the AGB and crop yield for the rest of the study area. The AGB and crop yield data were collected during the harvesting only.

The correlation and regression analyses were carried out to evaluate the relationship between the AGB and the plant height (the plant height obtained from the CSM), as well as between the crop yield and the plant height. A linear relationship between AGB per square meter and the plant height was established.

For crop yield estimation, two separate relationships against the plant height were established. The average spike weight per square meter and the average plant height for the corresponding plot's sample were used to establish a regression model. Similarly, the average grain weight per square meter and the average plant height for the corresponding plot's sample were used to establish another regression model. The coefficient of determination $\left(R^{2}\right)$ [31] and root mean square error (RMSE) [32] were obtained using Equations (1) and (2) respectively.

$$
R^{2}=\frac{\left[n \sum(x y)-\sum x \sum y\right]^{2}}{\left[n \sum x^{2}-\left(\sum x\right)^{2}\right] \times\left[n \sum y^{2}-\left(\sum y\right)^{2}\right]}
$$

where, x: plant height; y: AGB/spike/grain weight; n: sample size.

$$
R M S E=\sqrt{\frac{\sum_{i=1}^{n}\left(\text { Actual }_{i}-\text { Predicted }_{i}\right)^{2}}{n}}
$$


where, $\mathrm{n}$ is the sample size.

The developed regression equations were validated by assessing the predicted values against the independent field-based AGB and crop yield data. The workflow of the method is depicted in Figure 4.

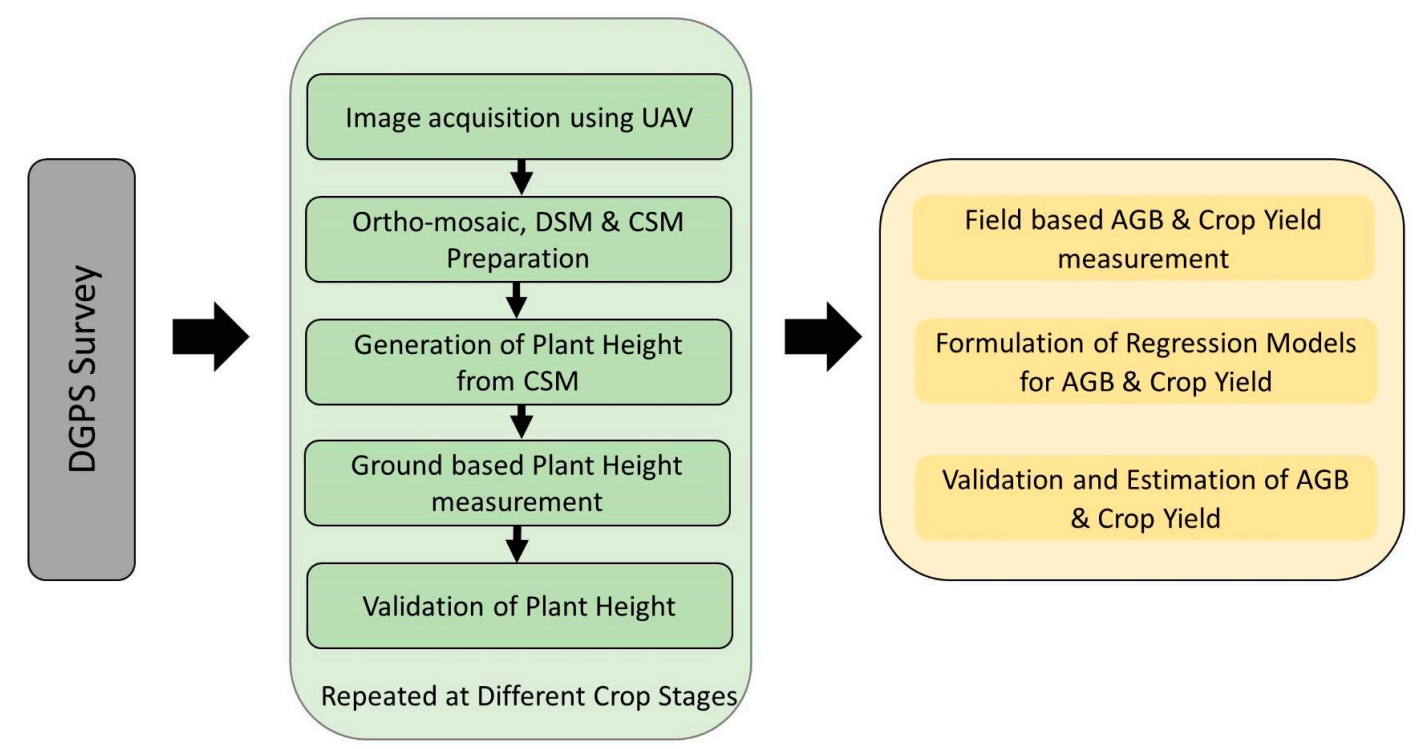

Figure 4. The methodological workflow of the study.

\section{Results}

\subsection{Ortho-Mosaic, CSM and Plant Height Generation}

Accuracy of ortho-mosaics provided RMSE ranging between 2 and $3 \mathrm{~cm}$ against independent checkpoints (Table 4). The ortho-mosaic of the study area, as well as the crop surface model (CSM) of March 2018, are depicted in Figure 5.

Table 4. Accuracy assessment of ortho-mosaics prepared from drone images from different wheat growth stages.

\begin{tabular}{ll}
\hline Image Acquisition Date & RMSE (m) \\
\hline 8 December 2017 & 0.02 \\
6 January 2018 & 0.02 \\
10 March 2018 & 0.03 \\
4 April 2018 & 0.03 \\
\hline
\end{tabular}

Plant height obtained from CSM had an error of $11.9 \%, 7.5 \%$, and $5 \%$ respectively for January, March, and April. The values were not significantly different for March and April. There was no change in plant height between heading and physiological maturity growth stages. The results show that Demonstration Plot D and Trial Plot T5 had the lowest average plant height in January. Demonstration Plot B and Trial Plot T4 had the highest plant height in the month. In March and April, Demonstration Plot B and Trial Plots T2, T4, and T8 had among the highest plant heights, while Demonstration Plot D and Trial Plot T7 had the lowest plant height. Average plant heights per plot across different growth stages obtained from CSM are depicted in Figure 6. 

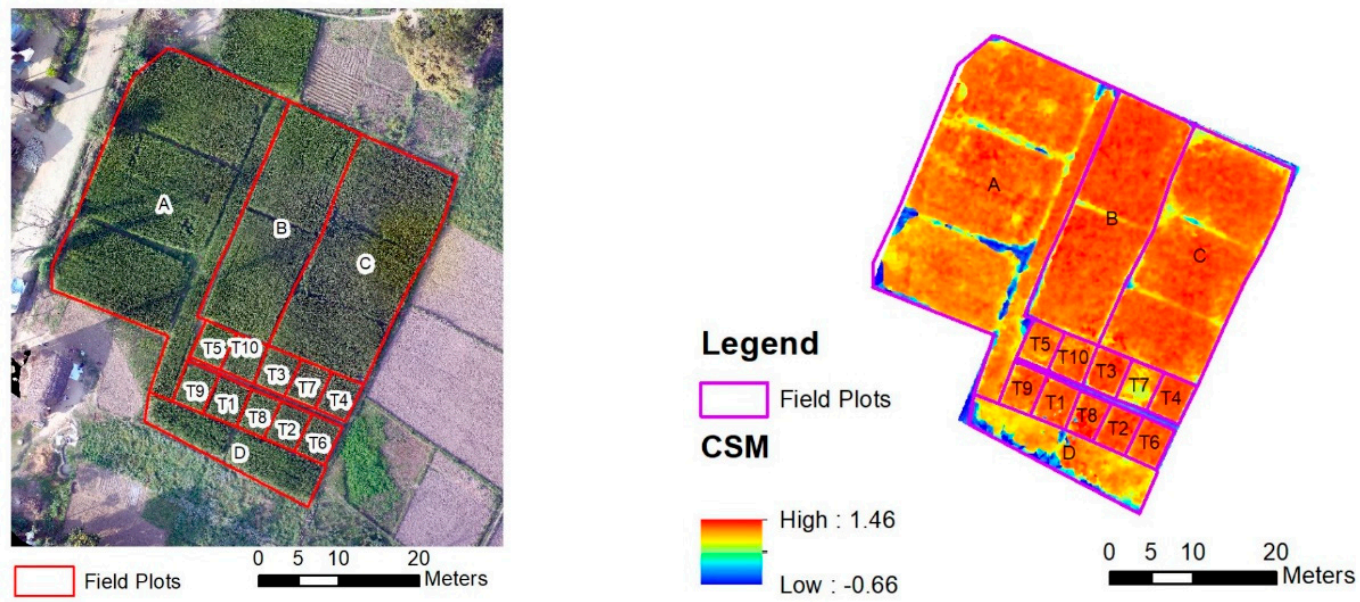

Figure 5. Field plots overlaid on the ortho-mosaic of the study area (left). Crop surface model (right). Both data are acquired/derived in March 2018.

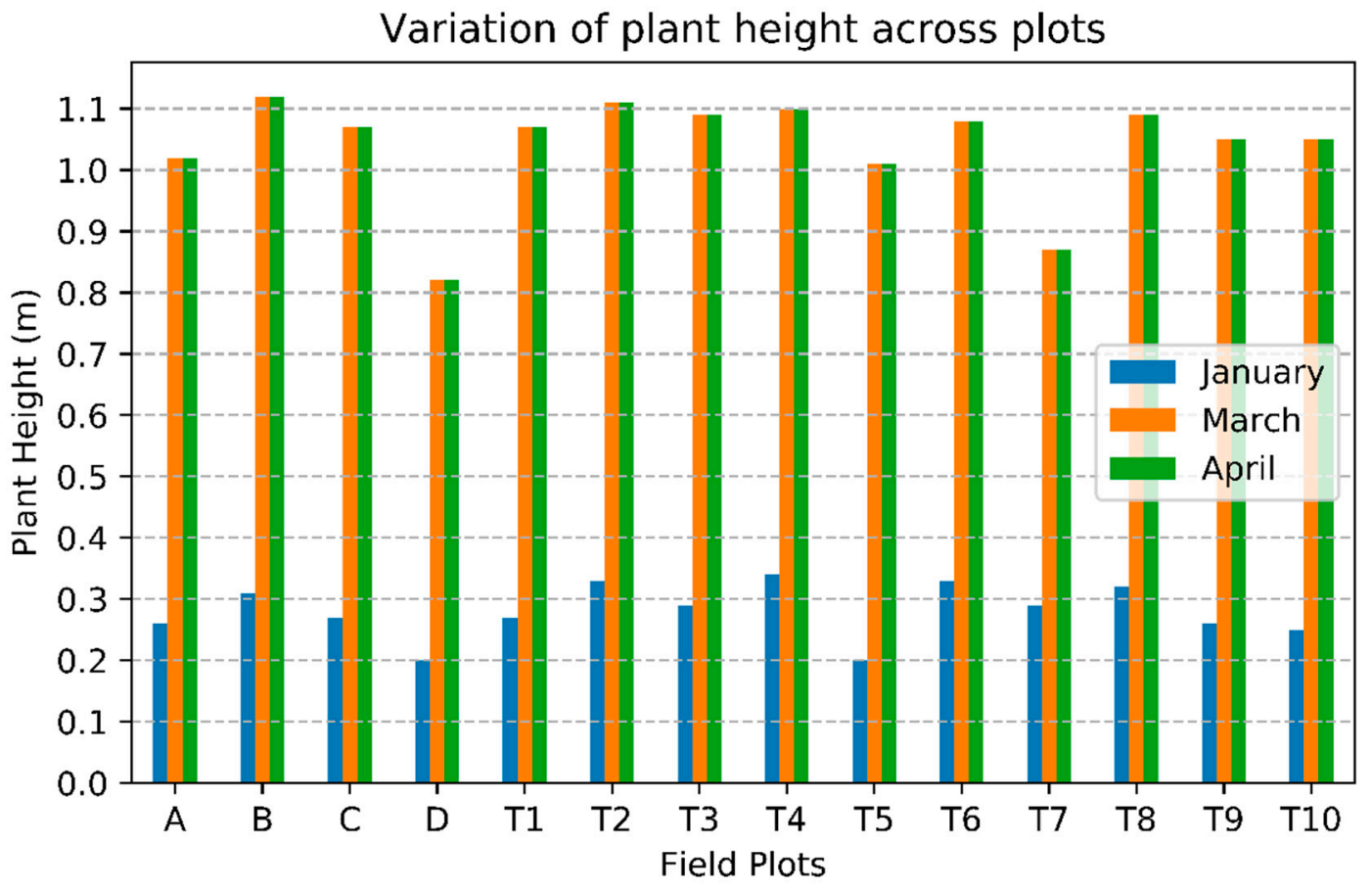

Figure 6. Time series analysis of average plant height across plots.

Correlating the average plant height of the plots with the amount and type of fertilizers and management practices, it is clear that the application of compost in Trial Plot T2 has led to the best crop growth among the trial plots. Similarly, manual line sowing of seeds and fertilizer in Plot B has yielded the best results among the demonstration plots. Moreover, the application of polymer-coated urea has a positive impact on the growth of wheat in trial plots T8 and T9. However, the application of rice fly ash and farm-yard manure (FYM) did not improve the crop growth in trial plots T3 and T10. It has to be noted that the average plant height will suffer to some extent due to the heterogeneity of plants within the plots as presented in the CSM (Figure 5).

\subsection{AGB Estimation}

Only wet AGB and yield were measured due to the unavailability of drying facilities. Moisture level, however, is supposed to be constant throughout the plots, which were very close, with homogeneous soil structure and topography. The minimum and maximum temperatures on harvesting were found 
to be $22^{\circ} \mathrm{C}$ and $39^{\circ} \mathrm{C}$ respectively. $\mathrm{AGB}$ data from trial plots $\mathrm{T} 1$ to $\mathrm{T} 8$ and those from demonstration plots A and B were utilized to form a regression equation (Equation (3)). The following equation represents the relationship:

$$
y=2.101 x-0.997
$$

where, $\mathrm{x}$ : plant height; $\mathrm{y}$ : AGB per square meter.

$R^{2}$ was found to be 0.66 . Relationship between AGB and plant height is presented in Figure 7.

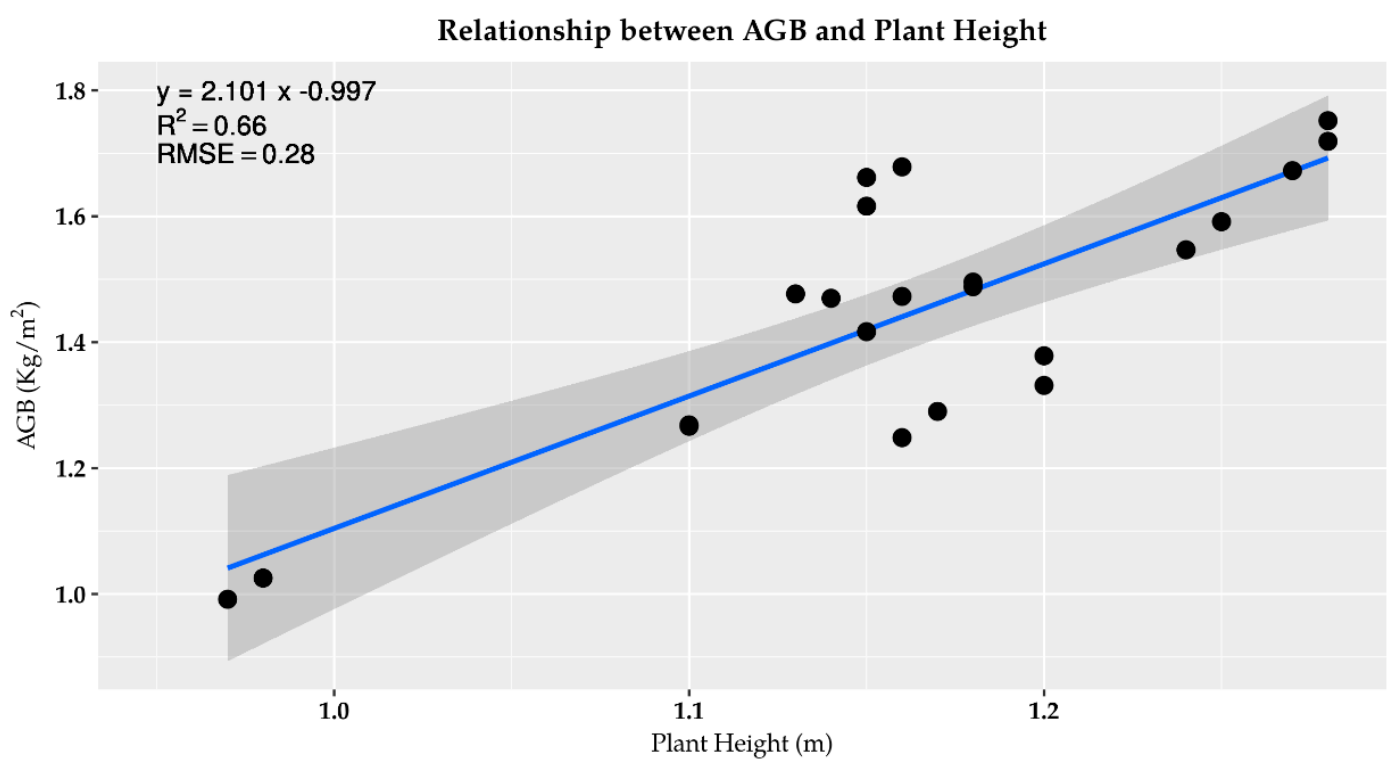

Figure 7. Relationship between above-ground biomass (AGB) and plant height. The plant height was derived from CSM.

The established regression model was validated using the predicted AGB against the field-based AGB measurement from trial plots T9 and T10, and demonstration plots $C$ and D. The AGB estimated from the model was within $13.4 \%$ of the weight measured in the field (Table 5).

Table 5. Validation of AGB. The AGB estimated with the regression model was validated against independent field-measured AGB samples.

\begin{tabular}{llll}
\hline Plot & Field Measured AGB $\left(\mathrm{Kg} / \mathbf{m}^{\mathbf{2}}\right)$ & Estimated AGB $\left(\mathrm{Kg} / \mathbf{m}^{\mathbf{2}}\right)$ & Error $(\%)$ \\
\hline T9 & 1.526 & 1.357 & 11.0 \\
T9 & 1.565 & 1.379 & 11.9 \\
T10 & 1.726 & 1.505 & 12.8 \\
T10 & 1.761 & 1.526 & 13.4 \\
C & 1.389 & 1.526 & -9.8 \\
C & 1.377 & 1.505 & -9.3 \\
C & 1.418 & 1.526 & -7.6 \\
D & 1.095 & 1.084 & 1.0 \\
D & 1.186 & 1.084 & 8.6 \\
D & 1.091 & 1.063 & 2.6 \\
\hline
\end{tabular}

Using the validated regression model of AGB and the plant height, the AGB for the entire study area was predicted to be 12.03 tons/ha.

\subsection{Crop Yield Estimation}

The sample locations for collecting field-based AGB and crop yield were used. Data from the same 22 locations were used for formulating regression equations for crop yield. A regression equation for 
spike weight and plant height and another equation for grain weight and plant height were established. Equation (4) represents the relationship between spike weight and plant height with an $R^{2}$ value of 0.73 :

$$
y=1.725 x-1.189
$$

where, $x$ : plant height; $y$ : spike weight per square meter.

Similarly, the following relationship (Equation (5)) between grain weight and plant height was established with an $R^{2}$ value of 0.70 :

$$
y=1.295 x-0.936
$$

where, $x$ : plant height; $y$ : grain weight per square meter.

While the relationship between spike weight and plant height is presented in Figure 8, the relationship between grain weight and plant height is presented in Figure 9.

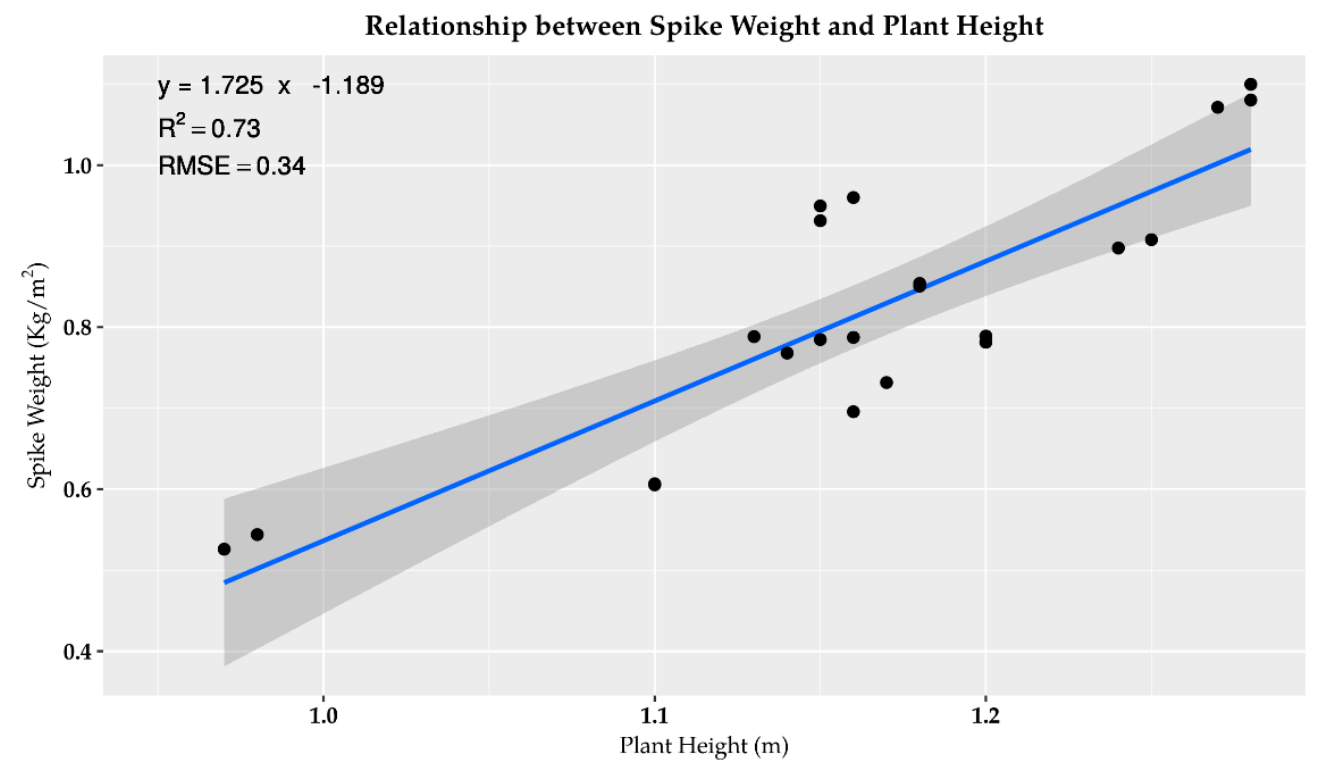

Figure 8. Relationship between spike weight and plant height. The spike weight was obtained from field samples, while the plant height was derived from CSM.

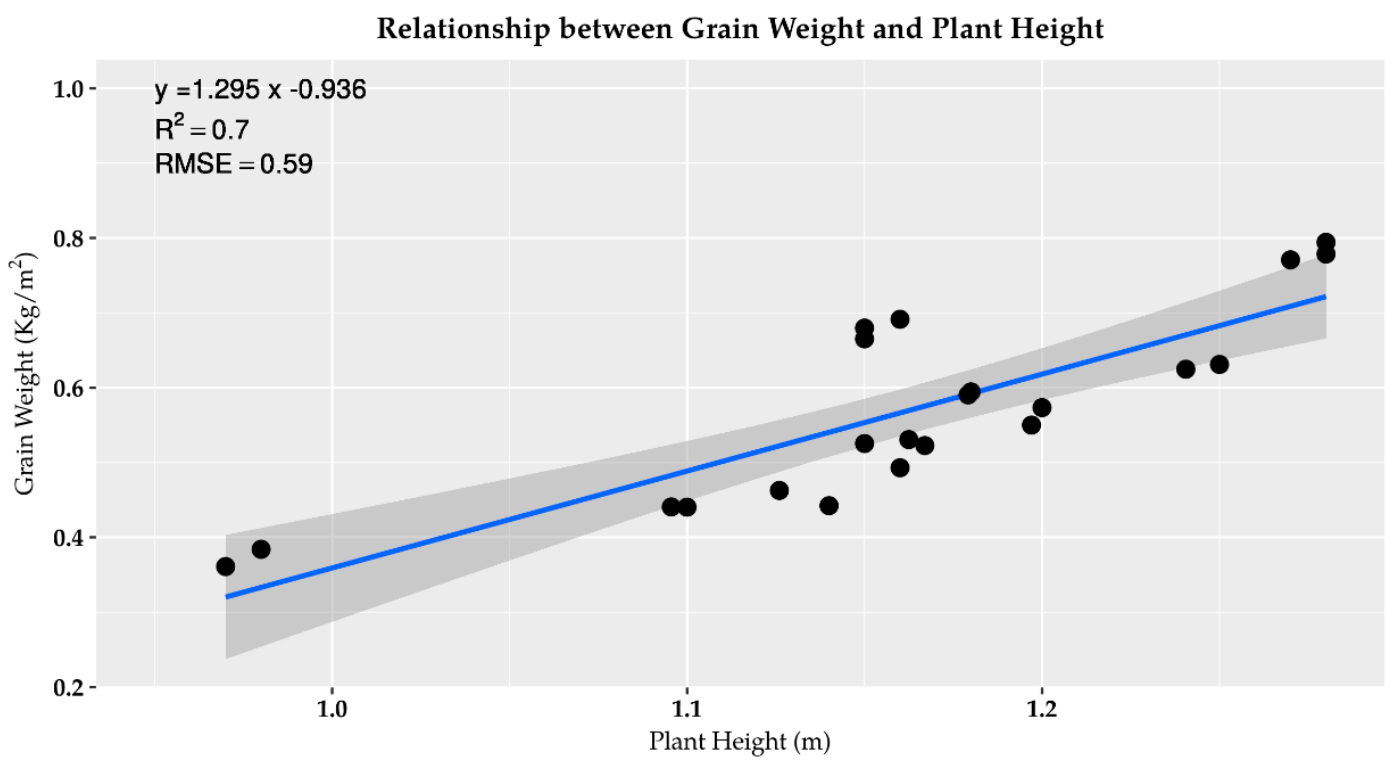

Figure 9. Relationship between grain weight and plant height. The grain weight was obtained from field samples while the plant height was derived from CSM. 
The established regression models for spike weight and grain weight were validated using the field-measured spike and grain weights, and the plant height of the respective sample plots obtained from the CSMs. Validation of spike weight results showed that the regression model is reasonable with low estimation errors except in the farmer's plot (Demonstration Plot D). The estimated and measured spike weights lay within $11.2 \%$, except for the farmer's plot. The error was high for the farmer's plot, which ranged from $16.8 \%$ to $22.8 \%$ (Table 6 ). Likewise, estimated grain weight had a maximum error of $14.3 \%$ for the trial plots T9, T10, and the demonstration plot C. However, the error was high (from $23.1 \%$ to $26.8 \%$ ) for the farmer's plot (Table 6 ).

Table 6. Validation of crop yield. Spike and grain weights estimated from regression models were validated using their corresponding independent field-measured samples data.

\begin{tabular}{llllllll}
\hline \multirow{2}{*}{ Plot } & \multicolumn{2}{l}{ Spike Weight $\left(\mathbf{K g} / \mathbf{m}^{\mathbf{2}}\right)$} & \multicolumn{4}{l}{ Grain Weight $\mathbf{( K g / \mathbf { m } ^ { 2 } )}$} & \multirow{2}{*}{ Remarks } \\
\cline { 2 - 6 } & $\begin{array}{l}\text { Field } \\
\text { Measured }\end{array}$ & Estimated & Error (\%) & $\begin{array}{l}\text { Field } \\
\text { Measured }\end{array}$ & Estimated & Error (\%) & \\
\hline T9 & 0.838 & 0.744 & 11.2 & 0.600 & 0.515 & 14.3 \\
T9 & 0.852 & 0.762 & 10.6 & 0.612 & 0.527 & 13.8 \\
T10 & 0.918 & 0.865 & 5.8 & 0.553 & 0.605 & -9.4 & \\
T10 & 0.932 & 0.882 & 5.3 & 0.625 & 0.618 & 1.1 & \\
C & 0.876 & 0.882 & -0.7 & 0.651 & 0.618 & 5.1 & \\
C & 0.892 & 0.865 & 3.0 & 0.632 & 0.605 & 4.2 & \\
C & 0.911 & 0.882 & 3.1 & 0.665 & 0.618 & 7.1 & Use of local seed variety. Inclusion of bare \\
D & 0.673 & 0.520 & 22.8 & 0.473 & 0.346 & 26.8 & soil height and height of weeds with smaller \\
D & 0.650 & 0.520 & 20.0 & 0.450 & 0.346 & 23.1 & heights besides wheat plants, in a CSM grid. \\
D & 0.604 & 0.503 & 16.8 & 0.439 & 0.333 & 24.1 & \\
\hline
\end{tabular}

Using the validated regression models of "Spike weight and plant height" and "Grain weight and plant height", spike and grain weights for the entire study area were predicted. The predicted spike and grain weights were found to be 6.54 tons/ha and 4.53 tons/ha respectively.

\section{Discussion}

\subsection{Data Sets and Accuracy}

Drone-based platforms provide ultra-high temporal and spatial resolutions data sets that facilitate frequent monitoring of crops and have evolved as an important support in precision agriculture $[33,34]$. Several studies have reported the use of different sensors and methods for precision agriculture: LiDAR [13,14,22,35]; near-infrared (NIR)-based indices [33,36,37]; and RGB indices [10,24,38]. However, these setups have largely been in the hands of farmers from the developed world, mainly because of the high cost of the systems and the technical know-how, system calibration for reliable RGB-based indices [35,37], for example. Our system setup encompasses a low-cost consumer-grade RGB-sensor based platform that the non-technical farmers in cooperative groups could use after a short training.

In line with previous studies $[10,15,16,22-25,35,38]$, we have found that the plant height measurement from drone-based images can be used to estimate the AGB and yield of wheat crop. Our results show an ortho-rectification accuracy of 2 to $3 \mathrm{~cm}$ (Table 4) with Pix4D software, which is equivalent to less than 2 to 3 pixels (at the rate of $1.1 \mathrm{~cm} /$ pixel). This ortho-rectification accuracy is quite expected [39]. Three-pixel errors obtained in the ortho-mosaics of March and April most probably be attributed to wind speed. Due to the larger plant height and moderate wind speed during the flights (during mid-day), the image matching may have performed poorly [40,41].

Validation of the average plant height obtained from CSMs provided an accuracy of $88 \%$ for January, $92.5 \%$ for March, and $95 \%$ for April. The accuracy of the plant height measurement in January seems lower than those in March and April, however, this is because of similar differences in plant height but with smaller reference data compared with later growth stages. In some sample sub-plots, however, errors were high. This is because those samples were collected from the edges of the plots. The wheat plants on the edges of the plots do not entirely cover the sample area. The sample area significantly includes bare soil and weeds with smaller heights as well. Therefore, the 
average plant height from the CSM is low for those sub-plots. However, the average plant height derived from the field measurement will not be influenced by the weeds and bare soil area because the height of the individual plants falling in the sampling area was measured and their average was determined. An $\mathrm{R}^{2}$ of 0.91 between terrestrial laser scanning (TLS)-derived and manually-measured plant heights, has been reported in [35]. We conclude that accuracy is comparable with those obtainable from high-cost technologies like LiDAR. Hence, the plant height estimated from low-cost drone-based images can be used as an alternative in developing countries to those obtainable with high-cost technologies like LiDAR, as well as labor-intensive manual ground-based measurements.

We found a moderate $\left(\mathrm{R}^{2}\right.$ of 0.66$)$ relationship between the AGB and the plant height. The relationship between crop yield and the plant height was stronger (with $\mathrm{R}^{2}$ of 0.73 and 0.70 respectively for the spike weight and the grain weight). Similar $\mathrm{R}^{2}$ values have been reported for biomass [23,25] and yield estimation [37] for different crops. Likewise, the $R^{2}$ value we have obtained lies in the range of what is reported between the plant height derived from CSM generated from the TLS point cloud and the rice AGB for linear $\left(\mathrm{R}^{2}\right.$ of 0.55 to 0.92$)$ and exponential ( $\mathrm{R}^{2}$ of 0.58 to 0.91$)$ models [15]. Estimated spike and grain weights of all plots, except the farmer's plot (Demonstration Plot D), differed by $11.2 \%$ and $14.3 \%$ (Table 6) from the corresponding field-based measurements. Higher error for Demonstration Plot D (which is up to $22.8 \%$ and $26.8 \%$ (Table 6) respectively for straw and grain weights) may be attributed to the use of local seed variety. The secondary reason for the large variation may be because of sparse wheat crops in the plot.

\subsection{Cost and Scalability}

Wheat crop monitoring and yield estimation using satellite-based remote sensing images is a challenging task because of the smaller average Nepalese farm size of 0.46 ha [12] and a short lifespan of approximately five months. While the spatial and temporal resolutions of freely available satellite images prohibit their applicability at the farm level, the cost associated with very high-resolution (VHR) satellite images bars temporal monitoring of such crops [42]. Wheat crops are generally grown by small-holder farmers in Nepal who grow the crop in smaller farms than the national average. The farmers further lack resources to use VHR or any other sophisticated system. However, consumer drones are low-cost, are easy to operate, and can provide ultra-high spatial and temporal resolution.

Cooperative farming has been gaining momentum in Nepalese society [43]. Several smallholder farmers form groups to practice homogeneous farming of particular crops with the use of comparatively improved farming practices. This arrangement of cooperative farming not only reduces the cost of inputs and attracts government subsidies, but also helps share resources and knowledge, and convenient marketing of their product. Because the cost of monitoring and yield estimation by using consumer-grade drones is inexpensive and the system is easy to operate, the cooperatives can afford and utilize the technology to monitor their crops, making informed decisions and thereby increasing yield. Hence, the system is also scalable with the support of cooperative farming systems. Plant height was measured by cooperative members in this research too. Thus, the cooperatives can properly utilize the system and operate it themselves if proper training is provided.

\section{Conclusions}

This study has supported the use of drone images in monitoring and yield estimation of wheat. The estimated wheat plant height from drone images having an error of $5 \%$ to $11.9 \%$ with respect to field-based measurements illustrated the support. Moreover, we investigated the relationship between the plant height derived from CSMs and AGB, and the plant height and crop yield. The $\mathrm{R}^{2}$ of 0.66 was found for AGB, and 0.73 and 0.70 were obtained for spike and grain weights (yield) respectively. With the linear regression models developed, AGB and crop yield maps were prepared. We conclude that plant height can be economically estimated with the use of images acquired with consumer-grade drones. Further, this study infers that wheat AGB and yield can be reasonably and competitively estimated by measuring plant height from crop surface models (CSMs) prepared from drone images. 
As an extension and further development of this research, we recommend increasing the size of the study area and individual plots. We firmly believe that this is likely to reveal the underpinning problem with spatial and temporal variability, providing a precise modeling opportunity to contribute to solutions to the food security issue.

Author Contributions: Conceptualization, U.S.P., N.S., S.M. and J.A.; Data curation, U.S.P., and N.S.; Funding acquisition, N.S., U.S.P., and K.L.S.; Drone flights, U.S.P. and N.S.; Investigation, U.S.P., N.S., S.M.; Methodology, U.S.P., N.S., and S.M.; J.A.; Project administration, N.S. and U.S.P.; Supervision, J.A.; Validation, U.S.P., N.S., and S.M.; Writing-original draft, U.S.P. and A.K.P., Writing—review and editing, U.S.P., A.K.P., N.S., S.M., K.L.S., S. and J.A. All authors have read and agreed to the published version of the manuscript.

Funding: This project is funded by the University Grant Commission (UGC) Nepal under the Faculty Research Grant (Grant code: FRG-73/74-Engg-01). The field support was provided by The International Maize and Wheat Improvement Center (CIMMYT), Nepal office.

Acknowledgments: The authors would like to acknowledge the support of Shangharsha Thapa and Kushal K.C. for performing DGPS surveying and field data collection. Further, the authors are thankful to Roshan Shah and Chandan Shilpakar for arranging field transportation and accommodation. We also appreciate the support from members of Farmers' Cooperative in collecting field-based data.

Conflicts of Interest: The authors declare no conflict of interest.

\section{References}

1. Ehrlich, P.R.; Harte, J. To feed the world in 2050 will require a global revolution. Proc. Natl. Acad. Sci. USA 2015, 112, 14743-14744. [CrossRef] [PubMed]

2. UN Sustainable Development Goals. Available online: https:/www.un.org/sustainabledevelopment/ sustainable-development-goals/ (accessed on 1 October 2019).

3. Gomiero, T. Soil degradation, land scarcity and food security: Reviewing a complex challenge. Sustainability 2016, 8, 281. [CrossRef]

4. Redfern, S.K.; Azzu, N.; Binamira, J.S. Rice in Southeast Asia: Facing risks and vulnerabilities to respond to climate change. Build. Resil. Adapt. Clim. Chang. Agric. Sect. 2012, 23, 295.

5. Wang, H.; Hall, C.A.S.; Scatena, F.N.; Fetcher, N.; Wu, W. Modeling the spatial and temporal variability in climate and primary productivity across the Luquillo Mountains, Puerto Rico. For. Ecol. Manag. 2003, 179, 69-94. [CrossRef]

6. Alexandratos, N.; Bruinsma, J. World Agriculture Towards 2030/2050: The 2012 Revision ESA Working Paper No. 12-03; Food and Agriculture Organization of the United Nations: Rome, Italy, 2012.

7. Gumma, M.K.; Gauchan, D.; Nelson, A.; Pandey, S.; Rala, A. Temporal changes in rice-growing area and their impact on livelihood over a decade: A case study of Nepal. Agric. Ecosyst. Environ. 2011, 142, 382-392. [CrossRef]

8. Rimal, B.; Zhang, L.; Stork, N.; Sloan, S.; Rijal, S. Urban expansion occurred at the expense of agricultural lands in the Tarai region of Nepal from 1989 to 2016. Sustainability 2018, 10, 1341. [CrossRef]

9. FAO. Coping with Water Scarcity in Agriculture; Food and Agriculture Organization of the United Nations: Rome, Italy, 2016.

10. Tilly, N.; Aasen, H.; Bareth, G. Fusion of plant height and vegetation indices for the estimation of barley biomass. Remote Sens. 2015, 7, 11449-11480. [CrossRef]

11. Devkota, N.; Phuyal, R.K. Climatic Impact on Wheat Production in Terai of Nepal. J. Dev. Adm. Stud. 2016, 23, 1-22. [CrossRef]

12. Family Farming Knowledge Platform-Smallholders Dataportrait. Available online: http://www.fao.org/ family-farming/data-sources/dataportrait/farm-size/en/ (accessed on 3 April 2020).

13. Hämmerle, M.; Höfle, B.; Höfle, B. Effects of reduced terrestrial LiDAR point density on high-resolution grain crop surface models in precision agriculture. Sensors 2014, 14, 24212-24230. [CrossRef]

14. Lumme, J.; Karjalainen, M.; Kaartinen, H.; Kukko, A.; Hyyppä, J.; Hyyppä, H.; Jaakkola, A.; Kleemola, J. Terrestrial laser scanning of agricultural crops. In Proceedings of the International Archives of the Photogrammetry, Remote Sensing and Spatial Information Sciences-ISPRS Archives, Beijing, China, 3-11 July 2008; pp. 563-566. 
15. Tilly, N.; Hoffmeister, D.; Cao, Q.; Lenz-Wiedemann, V.; Miao, Y.; Bareth, G. Transferability of Models for Estimating Paddy Rice Biomass from Spatial Plant Height Data. Agriculture 2015, 5, 538-560. [CrossRef]

16. Possoch, M.; Bieker, S.; Hoffmeister, D.; Bolten, A.A.; Schellberg, J.; Bareth, G. Multi-Temporal crop surface models combined with the rgb vegetation index from UAV-based images for forage monitoring in grassland. In Proceedings of the International Archives of the Photogrammetry, Remote Sensing and Spatial Information Sciences-ISPRS Archives, Prague, Czech Republic, 12-19 July 2016; p. 8.

17. Demir, N.; Sonmez, N.K.; Akar, T.; Unal, S. Automated Measurement of Plant Height of Wheat Genotypes Using a DSM Derived from UAV Imagery. In Proceedings of the 2nd International Electronic Conference on Remote Sensing, 22 March-5 April 2018; p. 5. Available online: https://www.mdpi.com/journal/ remotesensing/events/6369 (accessed on 10 June 2020).

18. Colomina, I.; Molina, P. Unmanned aerial systems for photogrammetry and remote sensing: A review. ISPRS J. Photogramm. Remote Sens. 2014, 92, 79-97. [CrossRef]

19. Melville, B.; Lucieer, A.; Aryal, J. Classification of Lowland Native Grassland Communities Using Hyperspectral Unmanned Aircraft System (UAS) Imagery in the Tasmanian Midlands. Drones 2019, 3, 5. [CrossRef]

20. Melville, B.; Lucieer, A.; Aryal, J. Assessing the impact of spectral resolution on classification of lowland native grassland communities based on field spectroscopy in Tasmania, Australia. Remote Sens. 2018, 10, 308. [CrossRef]

21. Adamchuk, V.I.; Ferguson, R.B.; Hergert, G.W. Soil Heterogeneity and Crop Growth. In Precision Crop Protection-The Challenge and Use of Heterogeneity; Oerke, E.C., Gerhards, R., Menz, G., Sikora, R., Eds.; Springer: Dordrecht, The Netherlands, 2010; pp. 3-16, ISBN 978-90-481-9277-9.

22. Ehlert, D.; Adamek, R.; Horn, H.J. Laser rangefinder-based measuring of crop biomass under field conditions. Precis. Agric. 2009, 10, 395-408. [CrossRef]

23. Bendig, J.; Bolten, A.; Bennertz, S.; Broscheit, J.; Eichfuss, S.; Bareth, G. Estimating biomass of barley using crop surface models (CSMs) derived from UAV-based RGB imaging. Remote Sens. 2014, 6, 10395-10412. [CrossRef]

24. Niu, Y.; Zhang, L.; Zhang, H.; Han, W.; Peng, X. Estimating above-ground biomass of maize using features derived from UAV-based RGB imagery. Remote Sens. 2019, 11, 1261. [CrossRef]

25. Acorsi, M.G.; Abati Miranda, F.D.D.; Martello, M.; Smaniotto, D.A.; Sartor, L.R. Estimating biomass of black oat using UAV-based RGB imaging. Agronomy 2019, 9, 344. [CrossRef]

26. Zhou, X.; Zheng, H.B.; Xu, X.Q.; He, J.Y.; Ge, X.K.; Yao, X.; Cheng, T.; Zhu, Y.; Cao, W.X.; Tian, Y.C. Predicting grain yield in rice using multi-temporal vegetation indices from UAV-based multispectral and digital imagery. ISPRS J. Photogramm. Remote Sens. 2017, 130, 246-255. [CrossRef]

27. Batistoti, J.; Marcato, J.; Ítavo, L.; Matsubara, E.; Gomes, E.; Oliveira, B.; Souza, M.; Siqueira, H.; Filho, G.S.; Akiyama, T.; et al. Estimating pasture biomass and canopy height in Brazilian Savanna using UAV photogrammetry. Remote Sens. 2019, 11, 2447. [CrossRef]

28. Song, Y.; Wang, J. Winter wheat canopy height extraction from UAV-based point cloud data with a moving cuboid filter. Remote Sens. 2019, 11, 1239. [CrossRef]

29. Adhikari, P.; Khatri-Chhetri, G.B.; Shrestha, S.M.; Marahatta, S. In-vitro study on prevalence of mycoflora in wheat seeds. J. Inst. Agric. Anim. Sci. 2015, 33-34, 27-34. [CrossRef]

30. Acevedo, E.; Silva, P.; Silva, H. Wheat Growth and Physiology. Available online: http://www.fao.org/3/ y4011e06.htm (accessed on 10 June 2020).

31. Textbook, E. (Ed.) Introductory Statistics; OpenStax College, Rice University: Houston, TX, USA, 2013; Volume 1, ISBN 978-1-304-89164-8.

32. Chai, T.; Draxler, R.R. Root mean square error (RMSE) or mean absolute error (MAE)? -Arguments against avoiding RMSE in the literature. Geosci. Model Dev. 2014, 7, 1247-1250. [CrossRef]

33. Hunt, E.R.; Dean Hively, W.; Fujikawa, S.J.; Linden, D.S.; Daughtry, C.S.T.; McCarty, G.W. Acquisition of NIR-green-blue digital photographs from unmanned aircraft for crop monitoring. Remote Sens. 2010, 2, 290-305. [CrossRef]

34. Berni, J.A.J.; Zarco-Tejada, P.J.; Suárez, L.; Fereres, E. Thermal and narrowband multispectral remote sensing for vegetation monitoring from an unmanned aerial vehicle. IEEE Trans. Geosci. Remote Sens. 2009, 47, 722-738. [CrossRef] 
35. Tilly, N.; Hoffmeister, D.; Cao, Q.; Huang, S.; Lenz-Wiedemann, V.; Miao, Y.; Bareth, G. Multitemporal crop surface models: Accurate plant height measurement and biomass estimation with terrestrial laser scanning in paddy rice. J. Appl. Remote Sens. 2014, 8, 083671. [CrossRef]

36. Hunt, E.; Hively, W.; McCarty, G.; Daughtry, C.; Forrestal, P.; Kratochvil, R.; Carr, J.; Allen, N.; Fox-Rabinovitz, J.; Miller, C. NIR-green-blue high-resolution digital images for assessment of winter cover crop biomass. GIScience Remote Sens. 2011, 48, 86-98. [CrossRef]

37. Swain, K.C.; Thomson, S.J.; Jayasuriya, H.P.W. Adoption of an unmanned helicopter for low-altitude remote sensing to estimate yield and total biomass of a rice crop. Trans. ASABE 2010, 53, 21-27. [CrossRef]

38. Ghebregziabher, Y.T. Monitoring Growth Development and Yield Estimation of Maize Using Very High-Resolution Uav-Images in Gronau, Germany; University of Twente: Enschede, The Netherlands, 2017.

39. Pix4D What Is Accuracy in an Aerial Mapping Project? Available online: https://www.pix4d.com/blog/ accuracy-aerial-mapping (accessed on 14 May 2020).

40. Wang, B.H.; Wang, D.B.; Ali, Z.A.; Ting Ting, B.; Wang, H. An overview of various kinds of wind effects on unmanned aerial vehicle. Meas. Control (UK) 2019, 52, 731-739. [CrossRef]

41. Dandois, J.P.; Olano, M.; Ellis, E.C. Optimal altitude, overlap, and weather conditions for computer vision uav estimates of forest structure. Remote Sens. 2015, 7, 13895-13920. [CrossRef]

42. Jin, X.; Kumar, L.; Li, Z.; Feng, H.; Xu, X.; Yang, G.; Wang, J. A review of data assimilation of remote sensing and crop models. Eur. J. Agron. 2018, 92, 141-152. [CrossRef]

43. Neupane, H.; Adhikari, M.; Rauniyar, P.B. Farmers' perception on role of cooperatives in agriculture practices of major cereal crops in Western Terai of Nepal. J. Inst. Agric. Anim. Sci. 2015, 33-34, 177-186. [CrossRef]

(C) 2020 by the authors. Licensee MDPI, Basel, Switzerland. This article is an open access article distributed under the terms and conditions of the Creative Commons Attribution (CC BY) license (http://creativecommons.org/licenses/by/4.0/). 